\title{
Association between NR5A2 and the risk of pancreatic cancer, especially among Caucasians: a meta-analysis of case-control studies
}

This article was published in the following Dove Press journal: OncoTargets and Therapy

\author{
Qun Chen ${ }^{1,2, *}$ \\ Hao Yuan ${ }^{1,2, *}$ \\ Guo-Dong Shi ${ }^{1,2, *}$ \\ Yang $\mathrm{Wu}^{1-3}$ \\ Dong-Fang Liu',2 \\ Yu-Ting Lin ${ }^{1,2}$ \\ Lei Chen ${ }^{1,2}$ \\ Wan-Li Ge ${ }^{1,2}$ \\ Kuirong Jiang ${ }^{1,2}$ \\ Yi Miao ${ }^{1,2}$
}

'Pancreas Center, The First Affiliated Hospital of Nanjing Medical University, Nanjing, China; ${ }^{2}$ Pancreas Institute, Nanjing Medical University, Nanjing, China; ${ }^{3}$ Division of Pancreatic Surgery, Department of General, Visceral, and Transplantation Surgery, Ludwig-Maximilians University,

Munich, Germany

*These authors contributed equally to this work

\begin{abstract}
Background: Previous studies have reported that nuclear receptor subfamily 5, group A, member 2 (NR5A2) polymorphisms (rs3790843 G > A, rs3790844 T >C, rs12029406 C > T) are associated with the risk of pancreatic cancer. However, the results of epidemiological investigations are still controversial. In order to explore its potential attributing factors, we pooled the updated literatures to evaluate the association between NR5A2 polymorphism and the risk of pancreatic cancer in this meta-analysis.
\end{abstract}

Materials and methods: Databases such as PubMed, Google Scholar and China National Knowledge Infrastructure were searched for eligible articles following strict inclusion and exclusion criteria (updated to November 18, 2017). Odds ratios (ORs) and $95 \%$ CIs were computed to assess the intensity of association. In addition, heterogeneity, sensitivity analysis and publication bias were explored. All statistical analyses were conducted by STATA 14.0.

Results: Our results showed that the rs 3790843 (GA vs GG: $\mathrm{OR}=0.86, \mathrm{CI}=0.76-0.98$, $P=0.992$; GA+AA vs GG: $\mathrm{OR}=0.83, \mathrm{CI}=0.73-0.94, P=0.950$; $\mathrm{A}$ vs $\mathrm{G}$ : $\mathrm{OR}=0.85, \mathrm{CI}=0.78-0.93$, $P=0.802$ ), rs3790844 (CC vs TT: $\mathrm{OR}=0.65, \mathrm{CI}=0.54-0.78, P=0.617$; $\mathrm{CC}$ vs $\mathrm{TT}+\mathrm{CT}$ : $\mathrm{OR}=0.73, \mathrm{CI}=0.62-0.85, P=0.742 ; \mathrm{C}$ vs T: $\mathrm{OR}=0.78, \mathrm{CI}=0.73-0.84, P=0.555)$ and $\mathrm{rs} 12029406$ (TT vs $\mathrm{CC}: \mathrm{OR}=0.73, \mathrm{CI}=0.61-0.89, P=0.483$; $\mathrm{TT}$ vs $\mathrm{CC}+\mathrm{CT}$ : $\mathrm{OR}=0.78, \mathrm{CI}=0.66-0.92$, $P=0.648$; $\mathrm{T}$ vs $\mathrm{C}: \mathrm{OR}=0.87, \mathrm{CI}=0.79-0.95, P=0.837$ ) polymorphisms were associated statistically with the risk of pancreatic cancer. Furthermore, the results of subgroup analysis showed that rs 3790843 and rs 3790844 polymorphisms were especially related to the risk of pancreatic cancer in Caucasian population.

Conclusion: Our results revealed that NR5A2 may have a protective effect on pancreatic cancer. However, more well-designed researches are needed to verify the relationship between NR5A2 polymorphisms and the risk of pancreatic cancer.

Keywords: NR5A2, polymorphism, rs3790844, pancreatic cancer, meta-analysis

\section{Introduction}

Pancreatic cancer is a highly aggressive and malignant tumor, in which the most frequent type of tissue is ductal adenocarcinoma. ${ }^{1}$ In the USA, about $85 \%$ of pancreatic cancer patients had already developed metastasized or unresectable lesions at the time of diagnosis and were expected to live 12 months at most. ${ }^{2,3}$ The mortality rates are still rising in our country (China). ${ }^{4}$ Although the cause of pancreatic cancer is not yet clear, its high mortality rate is closely related to the biologic characteristics of the tumor and the genetic factors. ${ }^{5}$ It has been shown that $10 \%$ of pancreatic cancer is caused by genetic mutations. ${ }^{6}$ Meanwhile, levels of molecular markers can be used to predict the prognosis of pancreatic cancer. ${ }^{7}$
Correspondence: Kuirong Jiang; Yi Miao Pancreas Center, The First Affiliated Hospital of Nanjing Medical University, 300 Guangzhou Road, Nanjing 210029, Jiangsu Province, China

Tel +86 $2568136629 ;+862568136590$ Fax +86258378I992

Email jiangkuirongnjmu@sina.com; miaoyi@njmu.edu.cn 
Nuclear receptor subfamily 5, group A, member 2 (NR5A2), also called as liver receptor homolog-1, is a member of orphan nuclear hormone receptors, which is highly expressed in the pancreas, liver, intestine and ovary and is involved in the balance of cholesterol, steroidogenesis and bile acid in the body. ${ }^{8,9}$ NR5A2 is located on chromosome $1 \mathrm{q} 32.1$, which is reported to play an important role in the stability of the pancreatic acinar cell. ${ }^{10}$ Murtaugh reported that the lack of NR5A2 will promote the mutation of Kras gene which can accelerate deterioration of pancreatic cancer. ${ }^{11}$ Human genome-wide association studies have suggested that there is a significant association between single-nucleotide polymorphisms (SNPs) of NR5A2 and the risk of pancreatic cancer. ${ }^{12}$ Among these SNPs, rs3790844 is the focus of our study.

Located in the first intron of NR5A2, the SNP rs3790843 is characterized by $\mathrm{G}>\mathrm{A}$, while rs3790844 is characterized by $\mathrm{T}>\mathrm{C} .{ }^{13}$ The SNP rs12029406, which is characterized by $\mathrm{C}>\mathrm{T}$, might influence the receptor activity, which, in turn, can change the disease risk and survival. ${ }^{20}$ After searching the databases, we found five articles focusing on the association between their polymorphisms and the risk of pancreatic cancer. ${ }^{18-22}$ In order to get rid of the limitations of a single trial and gain a result of comprehensive meaning, we combined the five studies using meta-analysis to confirm whether rs3790843, rs3790844 and rs12029406 polymorphisms would affect the risk of pancreatic cancer, which has never been done before.

\section{Materials and methods} Literature search

We searched for relevant publications using the following words and terms: "NR5A2", "polymorphism/variety" and "pancreatic cancer/pancreatic ductal adenocarcinoma" in databases such as PubMed, Google Scholar and the China National Knowledge Infrastructure, and all literatures were published before November 18, 2017. References to these literatures were also screened in order to prevent loss of any valuable data.

\section{Inclusion and exclusion criteria}

Eligible studies were selected according to the following inclusion criteria: 1) focusing on the association between NR5A2 polymorphism and the risk of pancreatic cancer, 2) a case-control study, 3) providing available and sufficient data of genotype frequencies for calculating an odds ratio (OR) with 95\% CI and 4) distribution of the genotype in case and control groups was in Hardy-Weinberg equilibrium (HWE).
The exclusion criteria were as follows: 1) non-case-control, pure cell or animal studies, 2) not related to the risk of pancreatic cancer and 3) not containing useful genotype frequency data.

\section{Data extraction}

Two authors (Q Chen, H Yuan) independently screened the literatures, extracted the relevant information and finally discussed disagreement. All the data were recorded in the standard form: first author's name, year of publication, country of population, control source, genotypic methods, number of genotypes in case-control groups and result of the HWE test. We set the total data of the case and control groups $>1,000$ as "sample size $\mathrm{Y}$ " and $<1,000$ as "sample size N". In addition, we classified the populations from USA, England and Germany as Caucasian, while those from China and Japan were identified as Asian for subgroup analysis.

\section{Genetic model}

$\mathrm{A}$ is the mutant allele of rs3790844 which includes two alleles $\mathrm{G}$ and $\mathrm{A}, \mathrm{C}$ is the mutant allele of rs3790844 and $\mathrm{T}$ is the mutant allele of rs12029406. We selected the heterozygous model (GA vs GG or CT vs TT or CT vs CC), homozygous model (AA vs GG or CC vs TT or TT vs CC), dominant model (GA+AA vs GG or $\mathrm{CT}+\mathrm{CC}$ vs $\mathrm{TT}$ or $\mathrm{CT}+\mathrm{TT}$ vs $\mathrm{CC})$, recessive model (AA vs $\mathrm{GG}+\mathrm{GA}$ or $\mathrm{CC}$ vs $\mathrm{TT}+\mathrm{CT}$ or TT vs $\mathrm{CC}+\mathrm{CT}$ ) and allele model (A vs $\mathrm{G}$ or $\mathrm{C}$ vs $\mathrm{T}$ or $\mathrm{T}$ vs $\mathrm{C}$ ) for further meta-analysis.

\section{Statistical analysis}

Our meta-analysis was conducted by Stata software (version 14.0; StataCorp LP, College Station, TX, USA). To assess the strength of association between NR5A2 polymorphism and the risk of pancreatic cancer, we calculated the OR together with 95\% CI for each genetic model. Furthermore, we evaluated the heterogeneity by Cochran's $Q$-statistic. ${ }^{14}$ A $P$-value $<0.1$ indicated significant heterogeneity. Another method to evaluate the heterogeneity is $I^{2}$, which represents the percentage of variance across the whole study. In general, values of $I^{2}<25 \%$ represent "low heterogeneity", while values $>75 \%$ represent "high heterogeneity". ${ }^{15}$ Statistically, $I^{2}>50 \%$ indicates that the heterogeneity is significant and the random-effects model was chosen. ${ }^{16}$ Otherwise, the fixed-effects model was used. ${ }^{17}$ Moreover, data with similar characteristics such as source of control (HB/PB), sample size (Y/N) and ethnicity of the population (Asian/Caucasian) were used for subgroup analysis. 
Sensitivity analyses were performed to assess the stability of the studies on the pooled ORs. A single study in the analysis was omitted each time to calculate the outcomes again. Publication bias was evaluated by using Begg's test and Egger's test, and $P<0.05$ indicated significant bias. HWE was checked by the goodness-of-fit chi-square test, and $P>0.05$ indicated the genetic balance of the population and that the data were from the same Mendelian group.

\section{Results}

\section{Literature selection and study characteristics}

The procedure of literature screening is shown in Figure 1. We found 24 articles related to NR5A2 polymorphism from PubMed, Google Scholar and China National Knowledge Infrastructure. According to the inclusion and exclusion criteria, 19 articles were excluded. Among the selected articles, 3 articles were reviews, 6 articles were not associated with the risk of pancreatic cancer and the other 10 articles lacked usable data for estimating an OR with $95 \%$ CI. Ultimately, a total of five literatures were included in the meta-analysis. ${ }^{18-22}$ Among them, four studies containing 2,212 cases and 2,932 controls surveyed the association between rs3790843 $\mathrm{G}>\mathrm{A}$ and pancreatic cancer risk, five articles on the relation between $\mathrm{rs} 3790844 \mathrm{~T}>\mathrm{C}$ and pancreatic cancer risk included 4,191 cases and 5,133 controls, and three publications containing 1,822 cases and 2,510 controls explored the correlation of rs $12029406 \mathrm{C}>\mathrm{T}$ with pancreatic cancer risk. One of the articles studied the association between NR5A2 polymorphism and the risk of pancreatic cancer not only from England but also from Germany with different genotyping methods. ${ }^{20}$ Data for different controls from the same study were considered as a separate data set, which can be used for all analyses. Study characteristics of each literature are shown in Table 1.

\section{NR5A2 rs3790843, rs3790844 and rs I 2029406 polymorphisms}

We first analyzed the association between rs3790843, rs3790844 and rs12029406 polymorphisms and the risk of pancreatic cancer in the overall population, and the forest plots are shown in Figures 2-4. Then, in order to explain the relationship between their polymorphisms and the risk of pancreatic cancer, we also performed the subgroup analyses by control source, sample size and ethnicity. All results are presented in Table 2 in detail.

\section{Overall effects for meta-analysis}

Of the studies, two articles suggested the association between rs3790843 G $>$ A and pancreatic cancer risk, three studies revealed an obvious association between rs3790844 $\mathrm{T}>\mathrm{C}$ and pancreatic cancer risk and one research showed the association between rs12029406 $\mathrm{C}>\mathrm{T}$ and pancreatic

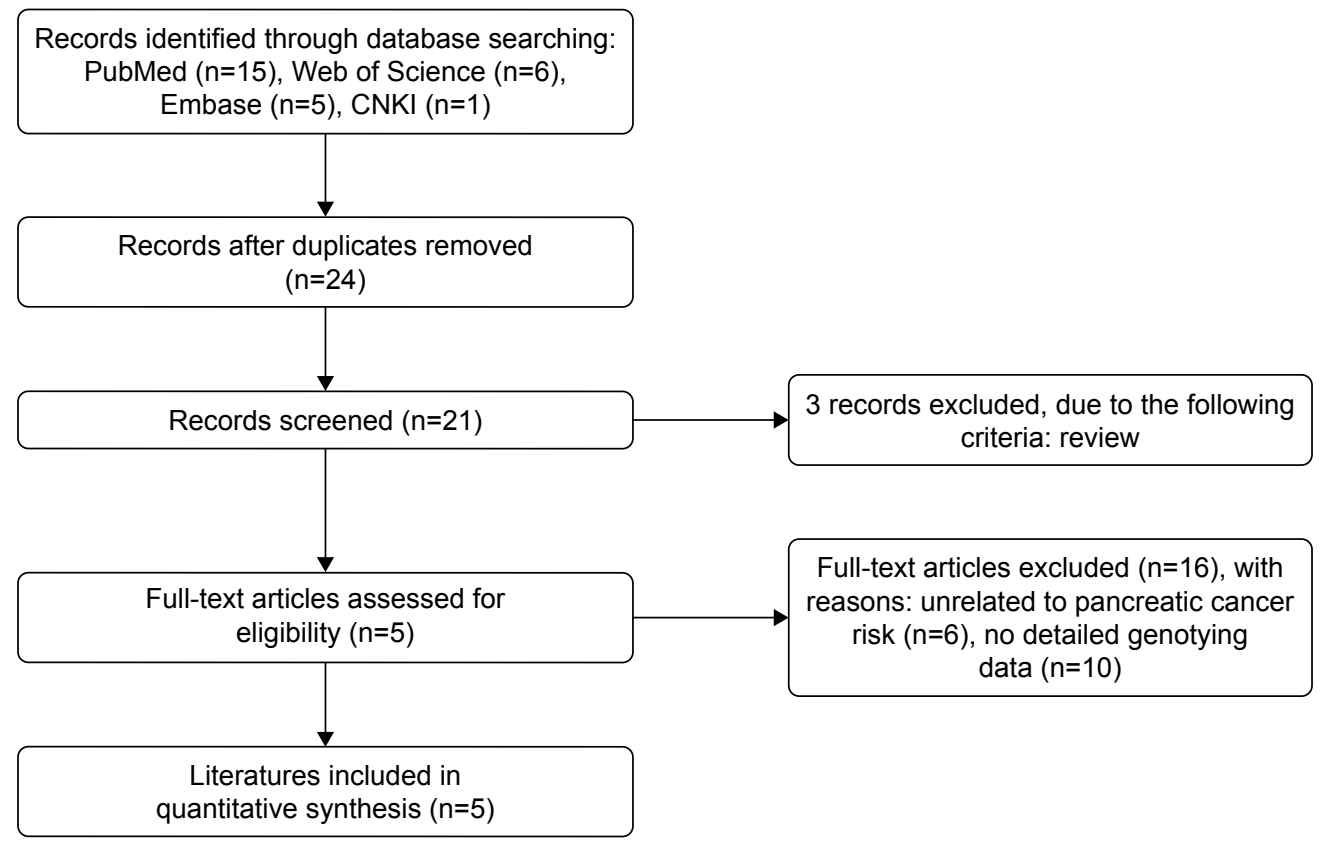

Figure I Flowchart of the literature selection process. Abbreviation: CNKI, China National Knowledge Infrastructure. 


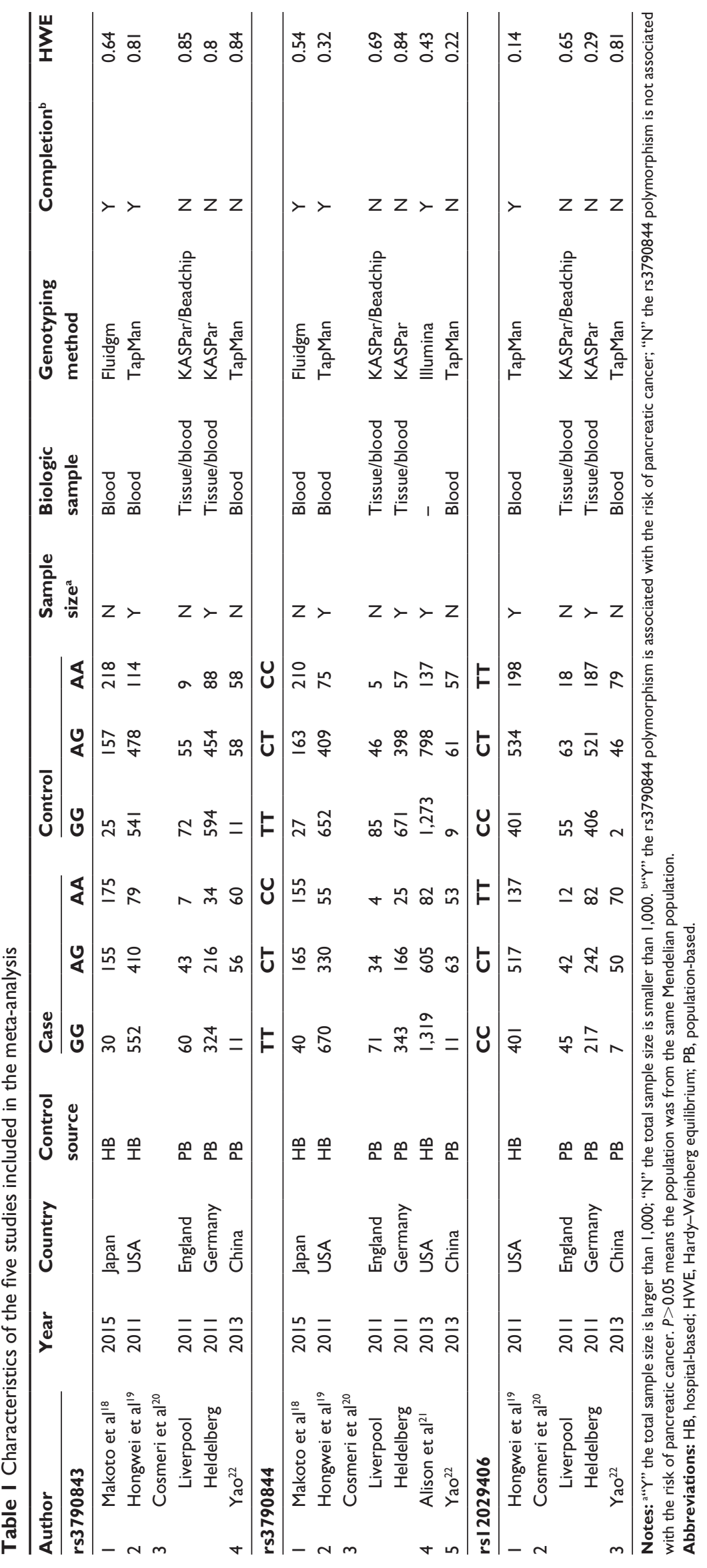


A

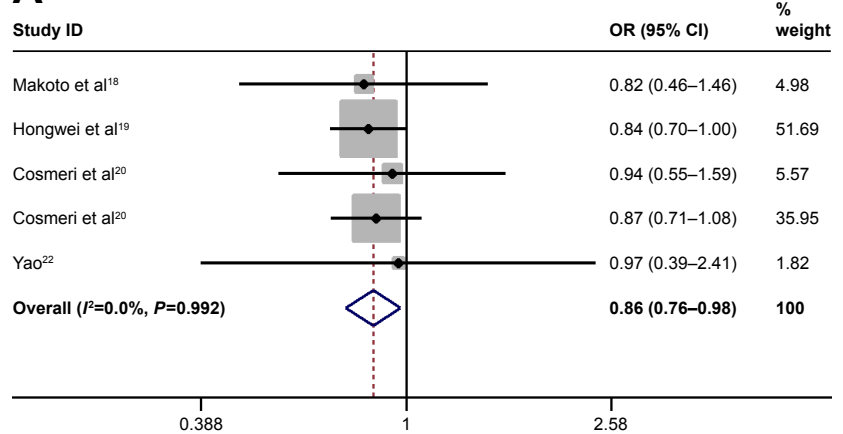

C

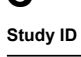

Makoto et al ${ }^{18}$

Hongwei et al ${ }^{19}$

Cosmeri et $\mathrm{al}^{20}$

Cosmeri et $\mathrm{al}^{20}$

$\mathrm{Yao}^{22}$

Overall $\left(l^{2}=0.0 \%, P=0.802\right)$

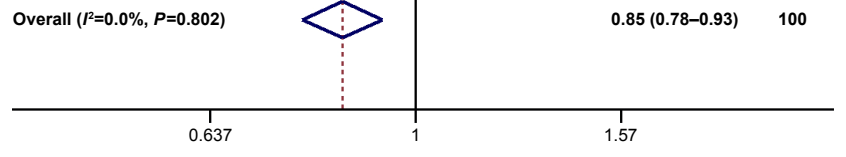

B

\begin{tabular}{|c|c|c|}
\hline Study ID & $\mathrm{OR}(95 \% \mathrm{Cl})$ & $\begin{array}{l}\% \\
\text { weight }\end{array}$ \\
\hline Makoto et al ${ }^{18}$ & $0.73(0.42-1.27)$ & 5.13 \\
\hline Hongwei et al ${ }^{19}$ & $0.81(0.68-0.96)$ & 52.11 \\
\hline Cosmeri et a $\left.\right|^{20}$ & $0.94(0.57-1.55)$ & 5.41 \\
\hline Cosmeri et a $\left.\right|^{20}$ & $0.85(0.69-1.03)$ & 35.60 \\
\hline $\mathrm{Yao}^{22}$ & $\rightarrow 1.00(0.42-2.40)$ & 1.74 \\
\hline Overall $\left(I^{2}=0.0 \%, P=0.950\right)$ & $0.83(0.73-0.94)$ & 100 \\
\hline 0.417 & 2.4 & \\
\hline
\end{tabular}

Figure 2 Forest plots of pancreatic cancer risk associated with NR5A2 rs3790843 G>A polymorphism.

Notes: (A) GA vs GG; (B) GA+AA vs GG; (C) A vs G.

Abbreviation: $O R$, odds ratio.

A

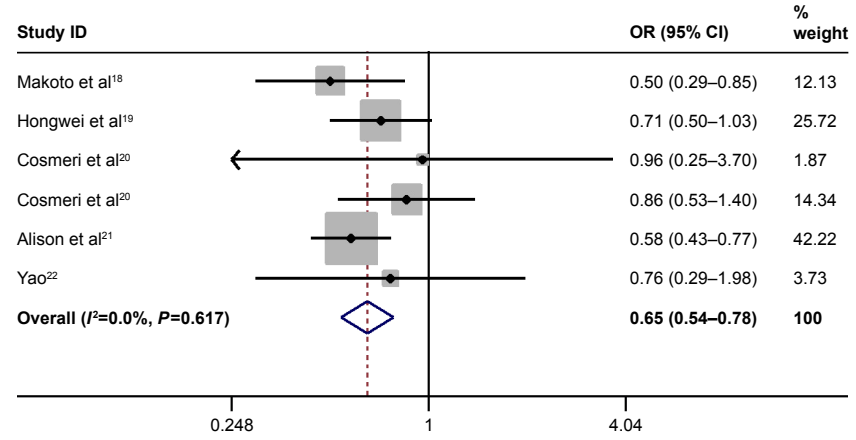

C
B

\begin{tabular}{|c|c|c|}
\hline Study ID & OR $(95 \% \mathrm{Cl})$ & $\begin{array}{l}\% \\
\text { weight }\end{array}$ \\
\hline Makoto et al ${ }^{18}$ & $0.68(0.51-0.91)$ & 29.31 \\
\hline Hongwei et al ${ }^{19}$ & $0.78(0.54-1.11)$ & 18.71 \\
\hline Cosmeri et a ${ }^{20}$ & $1.00(0.26-3.81)$ & 1.34 \\
\hline Cosmeri et $\mathrm{a}^{120}$ & $0.92(0.57-1.49)$ & 10.36 \\
\hline Alison et $\mathrm{al}^{21}$ & $0.64(0.49-0.85)$ & 30.54 \\
\hline $\mathrm{YaO}^{22}$ & $0.88(0.54-1.45)$ & 9.75 \\
\hline Overall $\left(I^{2}=0.0 \%, P=0.742\right)$ & $0.73(0.63-0.85)$ & 100 \\
\hline 0.261 & & \\
\hline
\end{tabular}

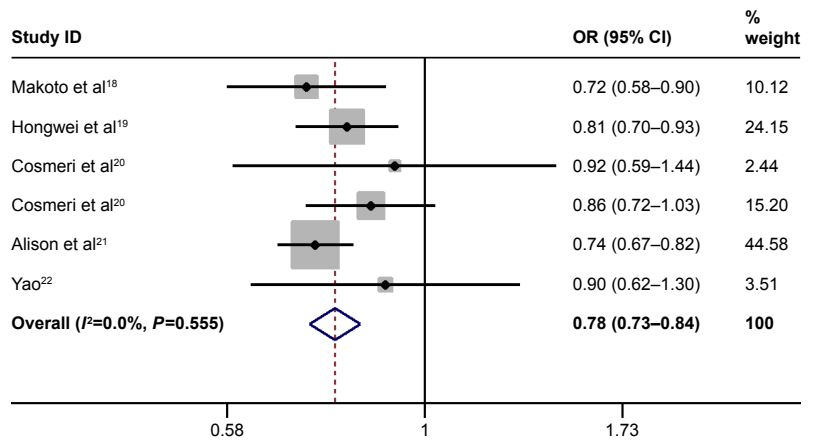

Figure 3 Forest plots of pancreatic cancer risk associated with NR5A2 rs3790844 T $>C$ polymorphism.

Notes: (A) CC vs TT; (B) CC vs TT+CT; (C) C vs T. Weights are from random-effects analysis.

Abbreviation: OR, odds ratio. 


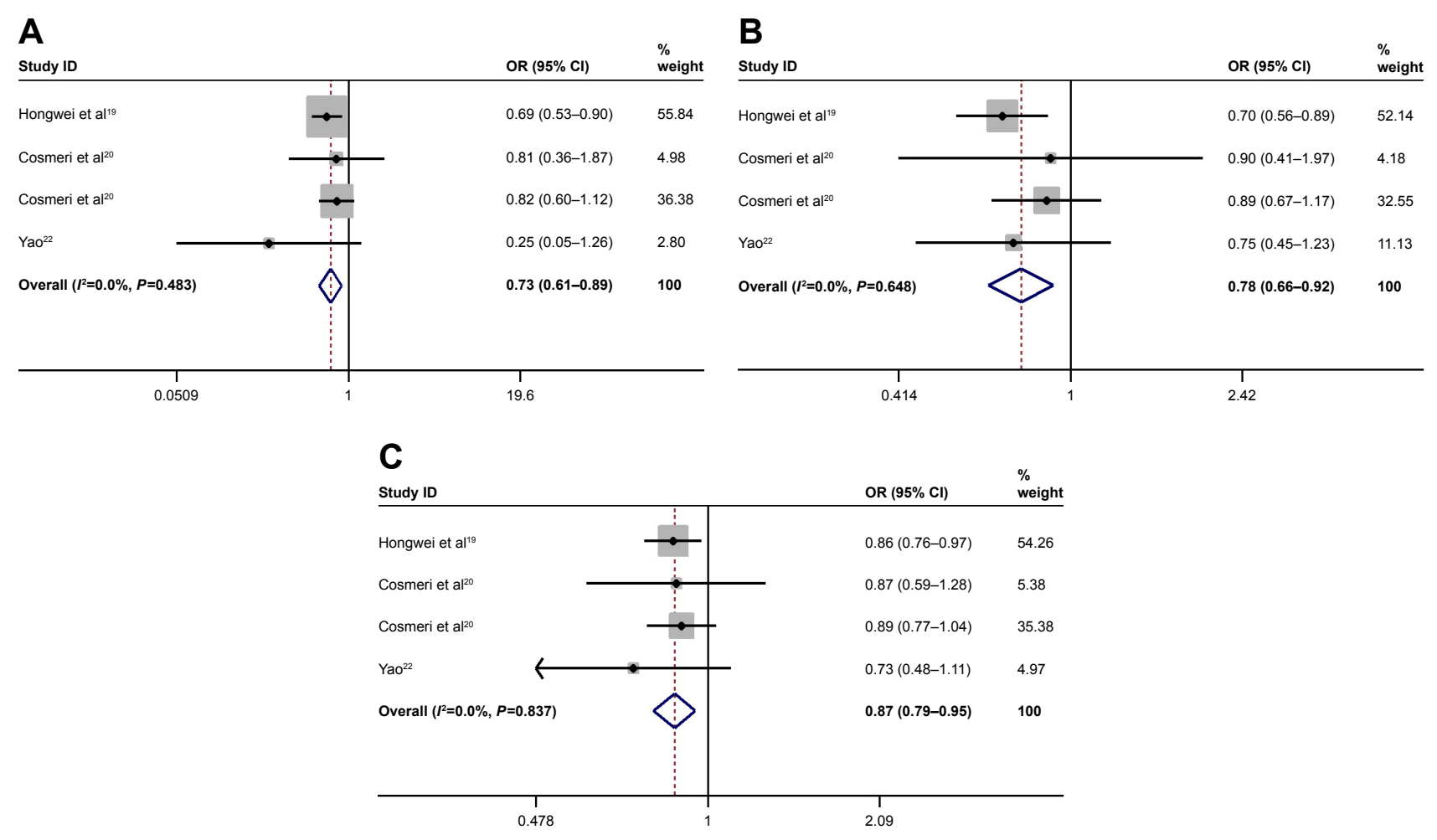

Figure 4 Forest plots of pancreatic cancer risk associated with NR5A2 rs 12029406 C $>$ T polymorphism.

Notes: (A) TT vs CC; (B) TT vs CC+CT; (C) T vs C.

Abbreviation: $O R$, odds ratio.

cancer risk. After analyzing the existing data, we found a significant association between rs3790843 polymorphism (GA vs GG: $\mathrm{OR}=0.86, \mathrm{CI}=0.76-0.98, P=0.992 ; \mathrm{GA}+\mathrm{AA}$ vs GG: $\mathrm{OR}=0.83, \mathrm{CI}=0.73-0.94, P=0.950$; A vs $\mathrm{G}: \mathrm{OR}=0.85$, $\mathrm{CI}=0.78-0.93, P=0.802$; Figure 2), rs3790844 polymorphism $(\mathrm{CC}$ vs TT: $\mathrm{OR}=0.65, \mathrm{CI}=0.54-0.78, P=0.617$; $\mathrm{CC}$ vs $\mathrm{TT}+\mathrm{CT}$ : $\mathrm{OR}=0.73, \mathrm{CI}=0.62-0.85, P=0.742 ; \mathrm{C}$ vs $\mathrm{T}$ : $\mathrm{OR}=0.78, \mathrm{CI}=0.73-0.84, P=0.555$; Figure 3 ) and rs 12029406 polymorphism (TT vs $\mathrm{CC}$ : $\mathrm{OR}=0.73, \mathrm{CI}=0.61-0.89, P=0.483$; TT vs $\mathrm{CC}+\mathrm{CT}$ : $\mathrm{OR}=0.78, \mathrm{CI}=0.66-0.92, P=0.648$; $\mathrm{T}$ vs $\mathrm{C}$ : $\mathrm{OR}=0.87, \mathrm{CI}=0.79-0.95, P=0.837$; Figure 4 ) and the risk of pancreatic cancer susceptibility.

\section{Subgroup analysis for control source}

Subgroup analysis was stratified by control sources. Statistically significant association between rs3790843 (GA vs GG: $\mathrm{OR}=0.84, \mathrm{CI}=0.71-0.99, P=0.944 ; \mathrm{GA}+\mathrm{AA}$ vs $\mathrm{GG}$ : $\mathrm{OR}=0.80, \mathrm{CI}=0.68-0.94, P=0.737$; $\mathrm{A}$ vs $\mathrm{G}: \mathrm{OR}=0.83$, $\mathrm{CI}=0.74-0.93, P=0.934$; Figure $\mathrm{S} 1)$ and $\mathrm{rs} 3790844(\mathrm{CC}$ vs TT: $\mathrm{OR}=0.61, \mathrm{CI}=0.49-0.74, P=0.495 ; \mathrm{CC}$ vs $\mathrm{TT}+\mathrm{CT}$ : $\mathrm{OR}=0.69, \mathrm{CI}=0.58-0.82, P=0.718 ; \mathrm{C}$ vs $\mathrm{T}: \mathrm{OR}=0.76$, $\mathrm{CI}=0.70-0.82, P=0.559$; Figure $\mathrm{S} 2$ ) polymorphisms with the risk of pancreatic cancer was detected in hospital-based studies under five genetic models.

\section{Subgroup analysis for sample size}

The sample size with sufficient statistical capacity is critical to the study and for the relationship between polymorphisms and the risk of cancer. We set the total data $>1,000$ as "Y" and $<1,000$ as "N". Statistically significant association between rs3790843 (GA vs GG: $\mathrm{OR}=0.85, \mathrm{CI}=0.75-0.98$, $P=0.793$; GA+AA vs GG: $\mathrm{OR}=0.82, \mathrm{CI}=0.72-0.94, P=0.745$; A vs G: $\mathrm{OR}=0.84, \mathrm{CI}=0.76-0.93, P=0.757$; Figure $\mathrm{S} 3$ ) and rs3790844 (CC vs TT: $\mathrm{OR}=0.66, \mathrm{CI}=0.54-0.82, P=0.344$; $\mathrm{CC}$ vs TT+CT: $\mathrm{OR}=0.73, \mathrm{CI}=0.63-0.85, P=0.411 ; \mathrm{C}$ vs T: $\mathrm{OR}=0.78, \mathrm{CI}=0.72-0.85, P=0.300$; Figure $\mathrm{S} 4$ ) polymorphisms and the risk of pancreatic cancer was also detected in "Y"-based studies under five genetic models.

\section{Subgroup analysis for ethnicity}

Subgroup analysis was stratified by ethnicity. The relationship between rs3790843 (GA vs GG: $\mathrm{OR}=0.86, \mathrm{CI}=0.76-0.98$, $P=0.912$; GA+AA vs GG: $\mathrm{OR}=0.83, \mathrm{CI}=0.73-0.94, P=0.843$; A vs G: $\mathrm{OR}=0.85, \mathrm{CI}=0.77-0.93, P=0.798$; Figure 5) and rs3790844 (CC vs TT: $\mathrm{OR}=0.67, \mathrm{CI}=0.55-0.82, P=0.491$; $\mathrm{CC}$ vs TT+CT: $\mathrm{OR}=0.73, \mathrm{CI}=0.60-0.89, P=0.575 ; \mathrm{C}$ vs T: $\mathrm{OR}=0.78, \mathrm{CI}=0.73-0.85, P=0.404$; Figure 6 ) polymorphisms and the risk of pancreatic cancer was detected from the data of Caucasian population. 


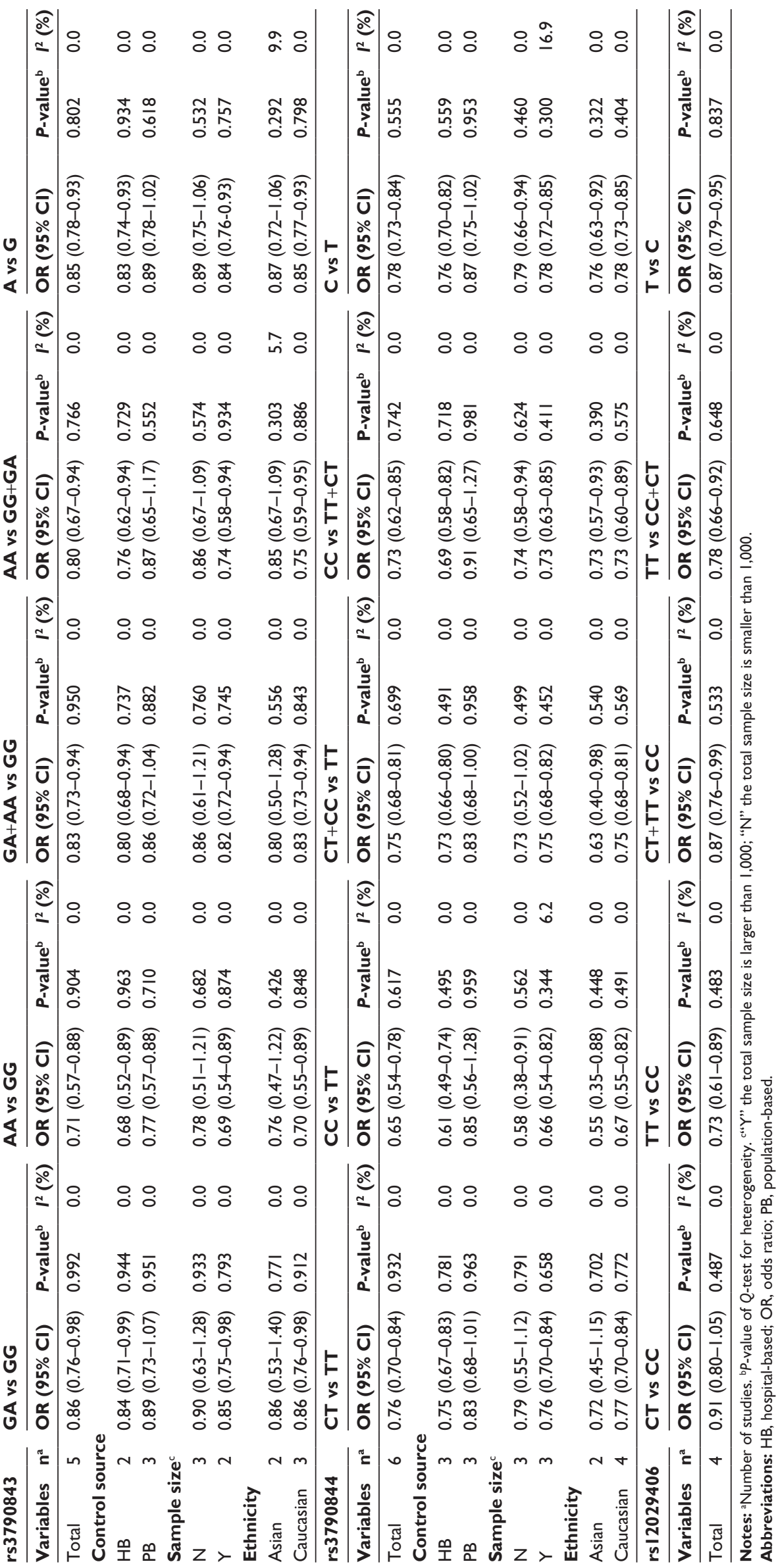


A

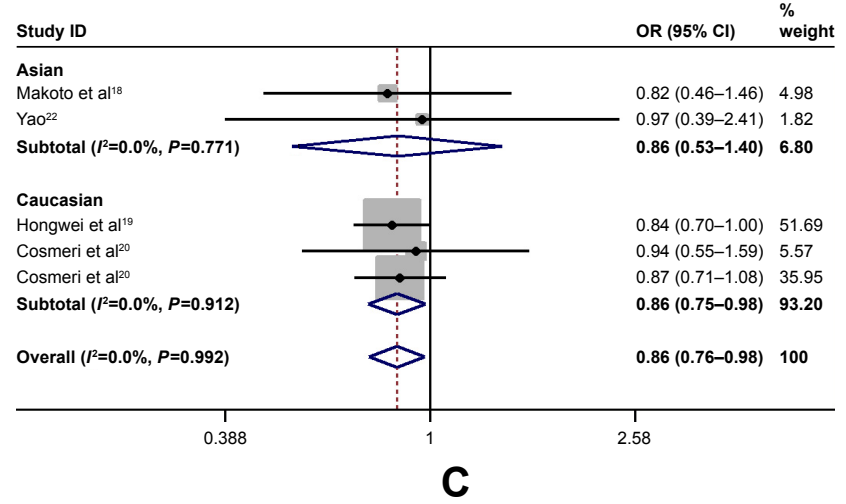

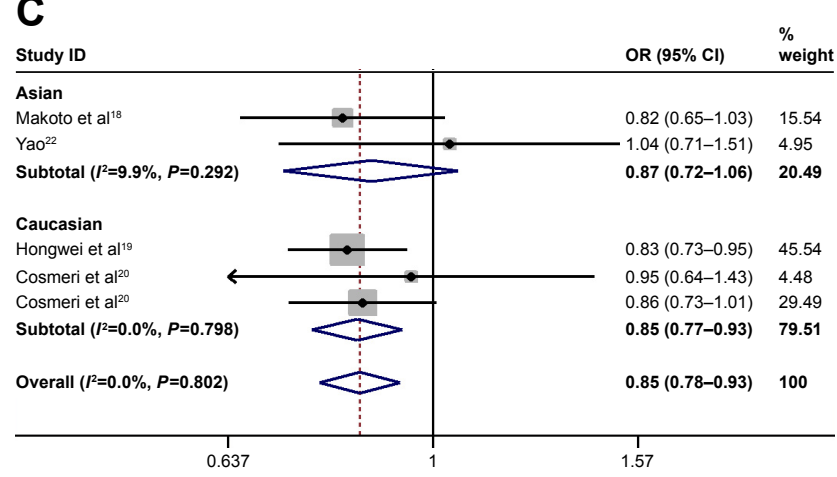

B

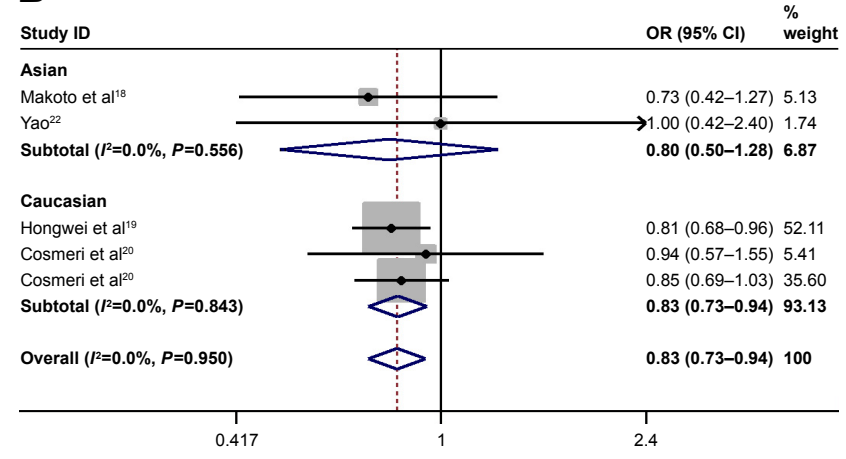

Figure 5 Subgroup analysis of ethnicity for NR5A2 rs3790843 G>A polymorphism and pancreatic cancer risk. Notes: (A) GA vs GG; (B) GA+AA vs GG; (C) A vs G.

Abbreviation: $O R$, odds ratio.

A

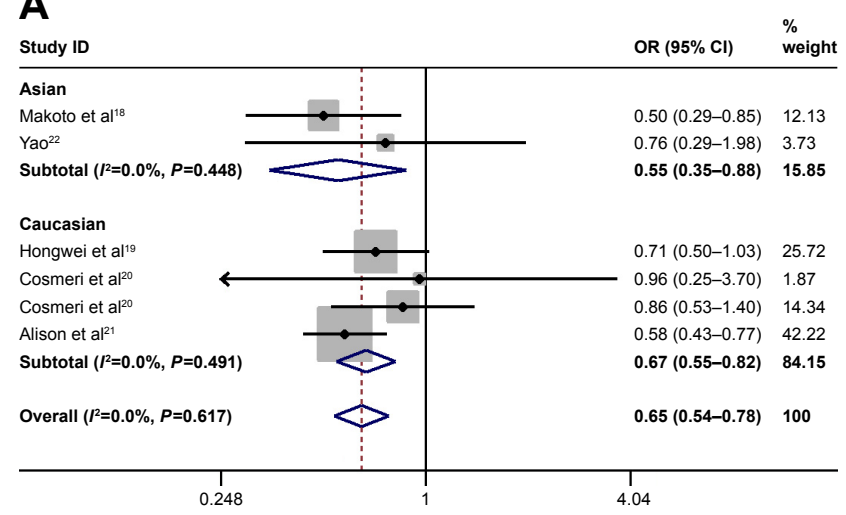

B

\begin{tabular}{|c|c|c|}
\hline Study ID & $\mathrm{OR}(95 \% \mathrm{Cl})$ & weigh \\
\hline \multicolumn{3}{|l|}{ Asian } \\
\hline Makoto et al ${ }^{18}$ & $0.68(0.51-0.91)$ & 29.31 \\
\hline $\mathrm{YaO}^{22}$ & $0.88(0.54-1.45)$ & 9.75 \\
\hline Subtotal $\left(I^{2}=0.0 \%, P=0.390\right)$ & $0.73(0.57-0.93)$ & 39.06 \\
\hline \multicolumn{3}{|l|}{ Caucasian } \\
\hline Hongwei et al ${ }^{19}$ & $0.78(0.54-1.11)$ & 18.71 \\
\hline Cosmeri et al20 & $1.00(0.26-3.81)$ & 1.34 \\
\hline Cosmeri et $\mathrm{a}^{20}$ & $0.92(0.57-1.49)$ & 10.36 \\
\hline Alison et $\mathrm{al}^{21}$ & $0.64(0.49-0.85)$ & 30.54 \\
\hline Subtotal $\left(I^{2}=0.0 \%, P=0.575\right)$ & $0.73(0.60-0.89)$ & 60.94 \\
\hline Overall $\left(I^{2}=0.0 \%, P=0.742\right)$ & $0.73(0.63-0.85)$ & 100 \\
\hline $\begin{array}{c}1 \\
0.261\end{array}$ & $\begin{array}{c}1 \\
3.82\end{array}$ & \\
\hline
\end{tabular}

\section{C}

\begin{tabular}{|c|c|c|}
\hline & OR $(95 \% \mathrm{Cl})$ & $\begin{array}{l}\% \\
\text { weight }\end{array}$ \\
\hline \multicolumn{3}{|l|}{ Asian } \\
\hline Makoto et al18 & $0.72(0.58-0.90)$ & 10.12 \\
\hline $\mathrm{Yao}^{22}$ & $0.90(0.62-1.30)$ & 3.51 \\
\hline Subtotal $\left(I^{2}=0.0 \%, P=0.322\right)$ & $0.76(0.63-0.92)$ & 13.63 \\
\hline \multicolumn{3}{|l|}{ Caucasian } \\
\hline Hongwei et al $1^{19}$ & $0.81(0.70-0.93)$ & 24.15 \\
\hline Cosmeri et al ${ }^{20}$ & $0.92(0.59-1.44)$ & 2.44 \\
\hline Cosmeri et $\mathrm{al}^{20}$ & $0.86(0.72-1.03)$ & 15.20 \\
\hline Alison et $\mathrm{al}^{21}$ & $0.74(0.67-0.82)$ & 44.58 \\
\hline Subtotal $\left(I^{2}=0.0 \%, P=0.404\right)$ & $0.78(0.73-0.84)$ & 86.37 \\
\hline Overall $\left(l^{2}=0.0 \%, P=0.555\right)$ & $0.78(0.73-0.84)$ & 100 \\
\hline $\begin{array}{c}T \\
0.5\end{array}$ & $\begin{array}{c}1.73 \\
1.73\end{array}$ & \\
\hline
\end{tabular}

Figure 6 Subgroup analysis of ethnicity for NR5A2 rs3790844 T >C polymorphism and pancreatic cancer risk.

Notes: (A) CC vs TT; (B) CC vs TT+CT; (C) C vs T. Weights are from random-effects analysis.

Abbreviation: OR, odds ratio. 
Table 3 The results of Begg's and Egger's tests

\begin{tabular}{|c|c|c|c|c|c|c|c|c|c|c|c|c|}
\hline \multirow[t]{3}{*}{ Risk model } & \multicolumn{4}{|c|}{ rs3790843 } & \multicolumn{4}{|c|}{ rs3790844 } & \multicolumn{4}{|c|}{ rs I 2029406} \\
\hline & \multicolumn{2}{|c|}{ Begg's test } & \multicolumn{2}{|c|}{ Egger's test } & \multicolumn{2}{|c|}{ Begg's test } & \multicolumn{2}{|c|}{ Egger's test } & \multicolumn{2}{|c|}{ Begg's test } & \multicolumn{2}{|c|}{ Egger's test } \\
\hline & $\mathbf{Z}$ & $P$-value & $\mathbf{Z}$ & $P$-value & $\mathbf{Z}$ & $P$-value & $t$ & $P$-value & $\mathbf{Z}$ & $P$-value & $t$ & $P$-value \\
\hline Heterozygous & 0.73 & 0.462 & 1.22 & 0.311 & 0.38 & 0.707 & 0.89 & 0.426 & 1.02 & 0.308 & -2.91 & 0.101 \\
\hline Homozygous & 1.22 & 0.221 & 2.76 & 0.070 & 0.00 & 1.000 & 0.92 & 0.408 & 0.34 & 0.734 & $-0.8 \mathrm{I}$ & 0.501 \\
\hline Dominant & 0.24 & 0.806 & 0.76 & 0.503 & 0.38 & 0.707 & 0.36 & 0.735 & 1.70 & 0.089 & -3.05 & 0.093 \\
\hline Recessive & 0.73 & 0.462 & 1.28 & 0.292 & 1.50 & 0.133 & 2.35 & 0.079 & 0.34 & 0.734 & 0.50 & 0.668 \\
\hline Allele & 1.22 & 0.221 & 2.45 & 0.091 & 0.75 & 0.452 & 1.55 & 0.196 & 0.34 & 0.734 & -0.99 & 0.428 \\
\hline
\end{tabular}

\section{Heterogeneity test}

Based on the Cochran's $Q$-statistic, all the data showed nonsignificant heterogeneity under five genetic models (Table 2).

\section{Sensitivity analysis}

In order to compare the differences and assess the sensitivity, a single study in the analysis was omitted each time to calculate the outcomes again. The pooled ORs were not influenced significantly, which indicated our results of this meta-analysis were stable (Figure S5).

\section{Publication bias analysis}

To evaluate the publication bias of the publications, Begg's test and Egger's test were performed. The funnel plots of five genetic models whose shapes were roughly symmetrical suggested no significant publication bias (figure not shown). Moreover, the results shown in Table 3 indicate that our results were reliable.

\section{Discussion}

As a highly malignant disease, pancreatic cancer is the fourth leading cause of cancer death in the USA. ${ }^{23}$ Most patients would have already progressed to an advanced stage with a poor cure rate when diagnosed. Surgical treatment is still the first choice to cure pancreatic cancer up to now, but only $15 \%-20 \%$ of patients have the opportunity to take it up..$^{24,25}$ What is worse, despite surgical resection, the majority of these patients would die from recurrence or metastasis in 2 years. ${ }^{26}$ Radiotherapy and chemotherapy, such as gemcitabine (Eli Lilly and Company, Indianapolis, IN, USA) or molecular-targeted drugs, are recommended for patients lacking the opportunity to undergo surgery. ${ }^{27,28}$ Disappointingly, the efficacy of these drugs to increase the survival rate is barely observed and unexplainable drug resistance comes up. Different from other cancers, the 5-year survival rate of pancreatic cancer has changed just a little in the past four decades (as low as 6\%). ${ }^{29}$ It has been shown that genetic factors play an important role in the development, progression and prognosis of pancreatic cancer. ${ }^{7,30,31}$ Exploring the genetic background of pancreatic cancer is instructive to find out some targets which can help in early diagnosis and judge the prognosis of pancreatic cancer.

Previous studies have shown that NR5A2, which is also known as liver receptor homolog-1, is an important regulator of pancreatic exocrine function. ${ }^{32}$ Lack of NR5A2, combined with pancreas-specific transcription factor 1 causes instability of pancreatic acinar cells, which increases the pancreatic injury and then causes mutations in the Kras gene. ${ }^{10,32-34}$ As we all know, mutation of Kras is the earliest event in deterioration of pancreatic cancer. ${ }^{11}$ We integrated the results of five studies and found a negative link between NR5A2 rs3790844 polymorphism and the risk of pancreatic cancer. However, histologic examinations show that NR5A2 is overexpressed in tumor tissues, which is quiet puzzling. ${ }^{35}$ Although the mechanism is not clear, it does not deny our conclusion that NR5A2 is a protective factor for early pancreatic cancer. Here, we put forward several possible explanations for discussion. Overexpression of NR5A2 is also closely related to diabetes and hyperlipidemia, which are the important risk factors for pancreatic cancer, and has a positive effect on mutation of Kras later in pancreatic cancer progression. ${ }^{11,36,37}$ Moreover, NR5A2 also contributes to other tumors. For instance, NR5A2 was reported to be involved in the metabolism of glutamine to induce hepatocellular carcinoma, while it also induces the expression and transcription of ER $\alpha$ and mediates the secretion of estrogen to affect the progression of breast cancer. ${ }^{38-40}$ In addition, NR5A2 is overexpressed in colon cancer and osteosarcoma cells. . $^{41,42}$ Recently, many studies have reported the relationship between the NR5A2 rs3790843, rs3790844 and rs12029406 polymorphisms and the risk of cholangiocarcinoma, gastric cancer and pancreatic cancer without consistent results. ${ }^{13,18-22,43}$ In order to clarify the association, we integrated the data of pancreatic cancer for the meta-analysis.

The polymorphism was observed to be related with pancreatic cancer in hospital-based studies, but not in populationbased studies in the subgroup analysis by the control source. 
Unsurprisingly, a larger sample bounded by 1,000 was more credible than a smaller sample in the relationship between them and cancer, which suggested that future research should require a larger sample size. Moreover, the subgroup analysis by ethnicity was also performed. The association between rs3790843 and rs3790844 polymorphisms and the risk of pancreatic cancer in Caucasian population under all genetic models was statistically significant; however, this was not found in the Asian population. Different genetic background or different lifestyles may lead to this difference between them and the total population.

As far as we know, this is the first meta-analysis of the association between NR5A2 (rs3790843, rs3790844, rs12029406) polymorphisms and the risk of pancreatic cancer. The analysis showed that the GA or AA genotype reduced the risk of pancreatic cancer and the A allele reduced the risk to 0.85 compared with the rs 3790843 polymorphism and the TC or CC genotype, which played a similar role in the rs3790844 polymorphism, and the $\mathrm{C}$ allele reduced the risk to 0.78 . Moreover, the TC or TT genotype of rs 12029406 could also protect from pancreatic cancer and the $\mathrm{T}$ allele reduced the risk to 0.87 . The largest value of $I^{2}$ was $16.9 \%(<25 \%)$, which means that no heterogeneity was found in all studies. Meanwhile, no abnormality was found in sensitivity analysis.

\section{Limitations}

There were some limitations in our meta-analysis which might have affected the final outcomes. First, the study was based on unadjusted OR values, which did not contain the well-known predisposing factors of pancreatic cancer, such as age, sex, alcohol, smoking, diabetes and chronic pancreatitis. Second, we lacked data from non-Caucasian populations in Africa in the subgroup analysis for ethnicity. Finally, different genotypic methods (Fluidgm, TapMan, KASPar and so on) could also have an impact on the outcome. More researches are needed to further analyze the association between NR5A2 polymorphism and the risk of pancreatic cancer.

\section{Conclusion}

Our study showed that the NR5RA rs3790843, rs3790844 and rs 12029406 polymorphisms were favorable factors in the risk of pancreatic cancer and were more protective in Caucasian population. If the mechanism behind this could be discovered by further research, hopefully, it will become a target for future personalized treatment of pancreatic cancer. Due to the limitations shown in this analysis, larger sample size and diverse studies are needed to confirm our results.

\section{Acknowledgment}

This work was supported by the Postgraduate Research and Practice Innovation Program of Jiangsu Province (KYCX17_1288).

\section{Disclosure}

The authors report no conflicts of interest in this work.

\section{References}

1. Ducreux M, Cuhna AS, Caramella C, et al; ESMO Guidelines Committee. Cancer of the pancreas: ESMO clinical practice guidelines for diagnosis, treatment and follow-up. Ann Oncol. 2015;26 (Suppl 5): v56-v68.

2. Vincent A, Herman J, Schulick R, Hruban RH, Goggins M. Pancreatic cancer. Lancet. 2011;378(9791):607-620.

3. Siegel RL, Miller KD, Jemal A. Cancer statistics, 2016. CA Cancer J Clin. 2016;66(1):7-30.

4. Chen W, Zheng R, Baade PD, et al. Cancer statistics in China, 2015. CA Cancer J Clin. 2016;66(2):115-132.

5. Liao X, Huang K, Huang R, et al. Genome-scale analysis to identify prognostic markers in patients with early-stage pancreatic ductal adenocarcinoma after pancreaticoduodenectomy. Onco Targets Ther. 2017;10:4493-4506.

6. Grover S, Syngal S. Hereditary pancreatic cancer. Gastroenterology. 2010;139(4):1076-1080.

7. Ansari D, Rosendahl A, Elebro J, Andersson R. Systematic review of immunohistochemical biomarkers to identify prognostic subgroups of patients with pancreatic cancer. Br J Surg. 2011;98(8): 1041-1055.

8. Lazarus KA, Wijayakumara D, Chand AL, Simpson ER, Clyne CD. Therapeutic potential of liver receptor homolog-1 modulators. J Steroid Biochem Mol Biol. 2012;130(3-5):138-146.

9. Lee YK, Moore DD. Liver receptor homolog-1, an emerging metabolic modulator. Front Biosci. 2008;13:5950-5958.

10. Guido VF, John PM, Christopher W, Matthias H. Nr5a2 maintains acinar cell differentiation and constrains oncogenic Kras-mediated pancreatic neoplastic initiation. Gut. 2014;63(4):656-664.

11. Murtaugh LC. Putting GWAS to the functional test: NR5A2 and pancreatic cancer risk. Gut. 2014;63(4):535-536.

12. Petersen GM, Amundadottir L, Fuchs CS, et al. A genome-wide association study identifies pancreatic cancer susceptibility loci on chromosomes 13q22.1, 1q32.1 and 5p15.33. Nat Genet. 2010;42(3):224-228.

13. Zhang X, Gu D, Du M, et al. Associations of NR5A2 gene polymorphisms with the clinicopathological characteristics and survival of gastric cancer. Int J Mol Sci. 2014;15(12):22902-22917.

14. Handoll HH. Systematic reviews on rehabilitation interventions. Arch Phys Med Rehabil. 2006;87:875.

15. Higgins JP, Thompson SG, Deeks JJ, Altman DG. Measuring inconsistency in meta-analyses. BMJ. 2003;327(7414):557-560.

16. DerSimonian R, Laird N. Meta-analysis in clinical trials. Control Clin Trials. 1986;7(3):177-188.

17. Mantel N, Haenszel W. Statistical aspects of the analysis of data from retrospective studies of disease. J Natl Cancer Inst. 1959;22(4): 719-748.

18. Makoto U, Shinichi O, Manabu M, et al. Genome-wide association study-identified SNPs (rs3790844, rs3790843) in the NR5A2 gene and risk of pancreatic cancer in Japanese. Sci Rep. 2015;5:17018.

19. Hongwei T, Xiaoqun D, Manal H, et al. Body mass index and obesityand diabetes-associated genotypes and risk for pancreatic cancer. Cancer Epidemiol Biomarkers Prev. 2011;20(5):779-792.

20. Cosmeri R, Daniele C, Nathalia G, et al. Pancreatic cancer susceptibility loci and their role in survival. PLoS One. 2011;6(11):e27921. 
21. Alison PK, Sara L, Julie BM, et al. An absolute risk model to identify individuals at elevated risk for pancreatic cancer in the general population. PLoS One. 2013;8(9):e72311.

22. Yao Y. A Case Control Study of Pancreatic Cancer with Environmental, Diease, Psychological, Behavioral Factors and the Preliminary Study of Genetic Predisposition in Pancreatic Cancer.caj [D]. Peking: Peking Union Medical College; 2013.

23. Siegel R, Ma J, Zou Z, Jemal A. Cancer statistics, 2014. CA Cancer J Clin. 2014;64(1):9-29.

24. Steele CW, Karim SA, Leach JDG, et al. CXCR2 inhibition profoundly suppresses metastases and augments immunotherapy in pancreatic ductal adenocarcinoma. Cancer Cell. 2016;29(6):832-845.

25. Ferrone CR, Pieretti-Vanmarcke R, Bloom JP, et al. Pancreatic ductal adenocarcinoma: long-term survival does not equal cure. Surgery. 2012;152(3 Suppl 1):S43-S49.

26. Siegel RL, Miller KD, Jemal A. Cancer statistics, 2015. CA Cancer J Clin. 2015;65(1):5-29.

27. Von Hoff DD, Ervin T, Arena FP, et al. Increased survival in pancreatic cancer with nab-paclitaxel plus gemcitabine. N Engl J Med. 2013; 369(18):1691-1703.

28. Hidalgo M. Pancreatic cancer. N Engl J Med. 2010;362(17): 1605-1617.

29. Shin EJ, Canto MI. Pancreatic cancer screening. Gastroenterol Clin North Am. 2012;41(1):143-157.

30. Kamisawa T, Wood LD, Itoi T, Takaori K. Pancreatic cancer. Lancet. 2016;388(10039):73-85.

31. Bailey P, Chang DK, Nones K, et al. Genomic analyses identify molecular subtypes of pancreatic cancer. Nature. 2016;531(7592):47-52.

32. Flandez M, Cendrowski J, Canamero M, et al. Nr5a2 heterozygosity sensitises to, and cooperates with, in ammation in KRasG12V-driven pancreatic tumourigenesis. Gut. 2014;63(4):647-655.

33. Holmstrom SR, Deering T, Swift GH, et al. LRH-1 and PTF1-L coregulate an exocrine pancreas-specific transcriptional network for digestive function. Genes Dev. 2011;25(16):1674-1679.
34. Carriere C, Young AL, Gunn JR, Longnecker DS, Korc M. Acute pancreatitis markedly accelerates pancreatic cancer progression in mice expressing oncogenic Kras. Biochem Biophys Res Commun. 2009; 382(3):561-565.

35. Benod C, Vinogradova MV, Jouravel N, Kim GE, Fletterick RJ, Sablin EP. Nuclear receptor liver receptor homologue 1 (LRH-1) regulates pancreatic cancer cell growth and proliferation. Proc Natl Acad Sci US A. 2011;108(41):16927-16931.

36. Dubois MJ, Bergeron S, Kim HJ, et al. The SHP-1 protein tyrosine phosphatase negatively modulates glucose homeostasis. Nat Med. 2006; 12(5):549-556.

37. Iwaki M, Matsuda M, Maeda N, et al. Induction of adiponectin, a fatderived antidiabetic and antiatherogenic factor, by nuclear receptors. Diabetes. 2003;52(7):1655-1663.

38. Xu P, Oosterveer MH, Stein S, et al. LRH-1-dependent programming of mitochondrial glutamine processing drives liver cancer. Genes Dev. 2016;30(11):1255-1260.

39. Zhu J, Zou Z, Nie P, et al. Downregulation of microRNA-27b-3p enhances tamoxifen resistance in breast cancer by increasing NR5A2 and CREB1 expression. Cell Death Dis. 2016;7(11):e2454.

40. Annicotte JS, Chavey C, Servant N, et al. The nuclear receptor liver receptor homolog-1 is an estrogen receptor target gene. Oncogene. 2005;24(55):8167-8175.

41. Yuan Q, Cao G, Li J, Zhang Y, Yang W. MicroRNA-136 inhibits colon cancer cell proliferation and invasion through targeting liver receptor homolog-1/Wnt signaling. Gene. 2017;628:48-55.

42. Li Z, Wu S, Lv S, Wang H, Wang Y, Guo Q. Suppression of liver receptor homolog-1 by microRNA-451 represses the proliferation of osteosarcoma cells. Biochem Biophys Res Commun. 2015;461(3):450-455.

43. Zimmer V, Mihalache F, Höblinger A, et al. The frequent NR5A2 gene variant rs3790844 mediates an increased risk of cholangiocarcinoma in a large European cohort. Z Gastroenterol. 2011;49:429. 


\section{Supplementary materials}

A

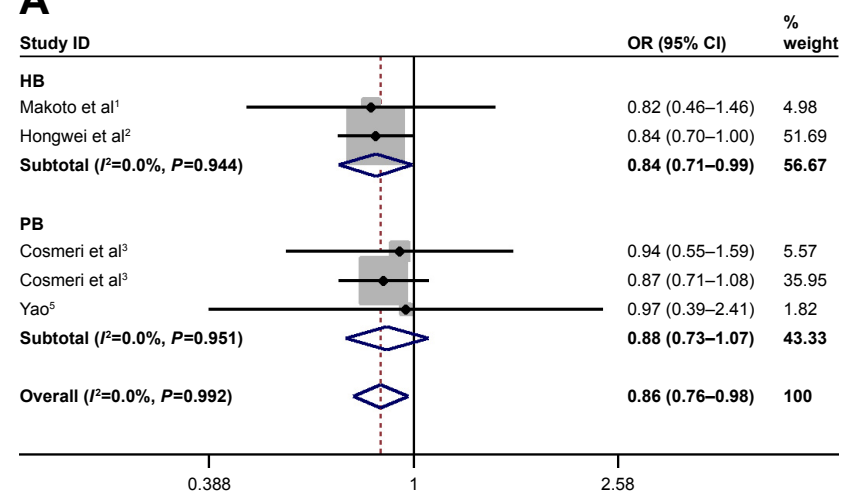

B

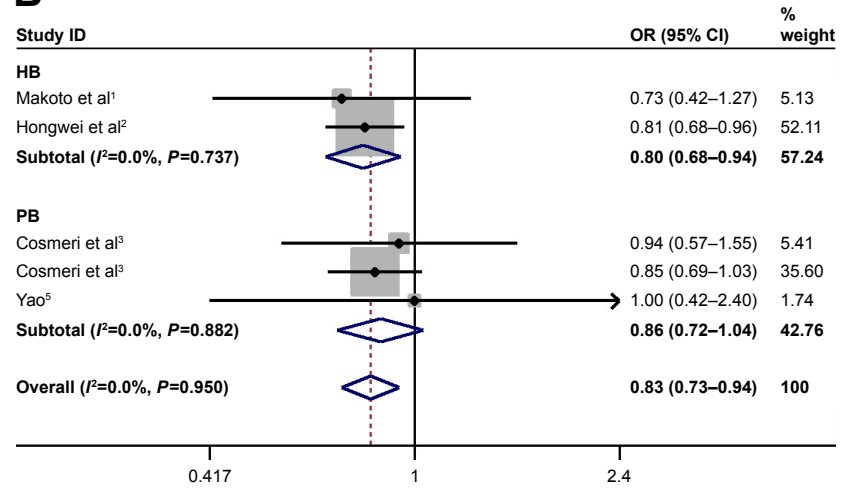

C

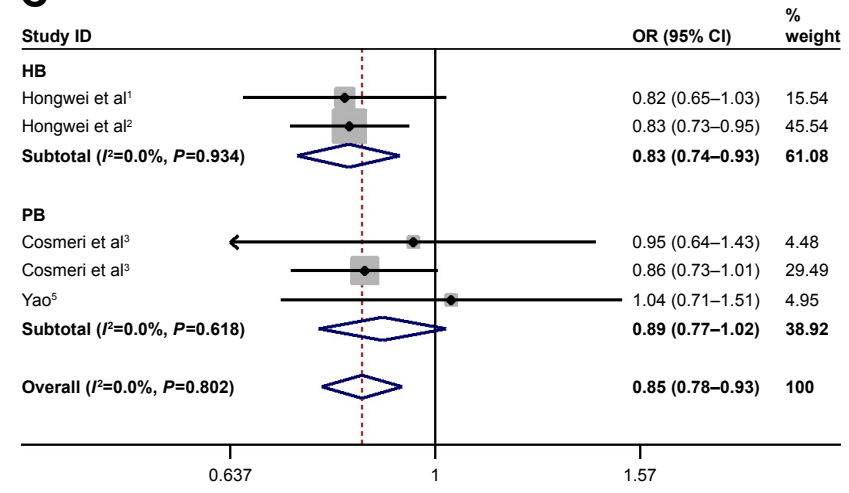

Figure SI Subgroup analysis of type of control source for NR5A2 rs3790843 G>A polymorphism and pancreatic cancer risk. Notes: (A) GA vs GG; (B) GA+AA vs GG; (C) A vs G.

Abbreviations: $\mathrm{HB}$, hospital-based; OR, odds ratio; $\mathrm{PB}$, population-based.

A

Study ID

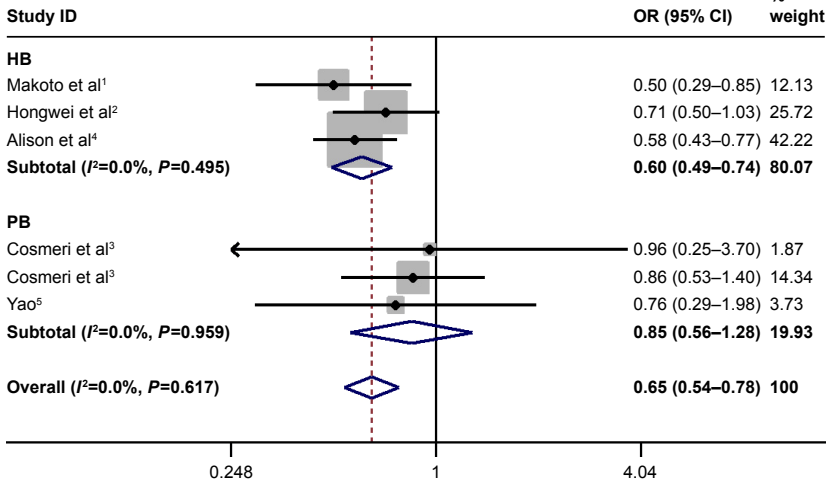

B

$\begin{array}{lll}\text { Study ID } & \text { OR }(95 \% \mathrm{Cl}) & \% \\ \text { weight }\end{array}$

HB

Makoto et al ${ }^{1}$

Hongwei et al ${ }^{2}$

Alison et $\mathrm{al}^{4}$

Subtotal $\left(l^{2}=0.0 \%, P=0.718\right)$

PB

Cosmeri et al $\left.\right|^{3}$

Cosmeri et al ${ }^{3}$

$\mathrm{YaO}^{5}$

Subtotal $\left(I^{2}=0.0 \%, P=0.981\right)$

Overall $\left(I^{2}=0.0 \%, P=0.742\right)$
$0.68(0.51-0.91) \quad 29.31$ $0.78(0.54-1.11) \quad 18.71$ $0.64(0.49-0.85) \quad 30.54$ $0.69(0.58-0.82) \quad 78.56$

$.00(0.26-3.81) 1.34$ $0.92(0.57-1.49) \quad 10.36$ $0.88(0.54-1.45) \quad 9.75$ $0.91(0.65-1.27) \quad 21.44$

$0.73(0.63-0.85) \quad 100$

Figure S2 (Continued) 


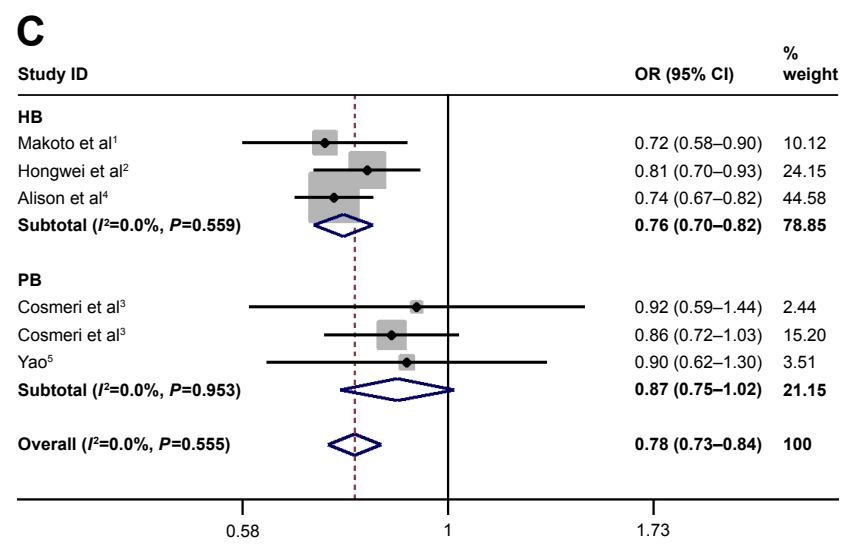

Figure S2 Subgroup analysis of type of control source for NR5A2 rs3790844 T>C polymorphism and pancreatic cancer risk. Notes: (A) CC vs TT; (B) CC vs TT+CT; (C) C vs T. Weights are from random-effects analysis.

Abbreviations: $\mathrm{HB}$, hospital-based; $\mathrm{OR}$, odds ratio; $\mathrm{PB}$, population-based.

A

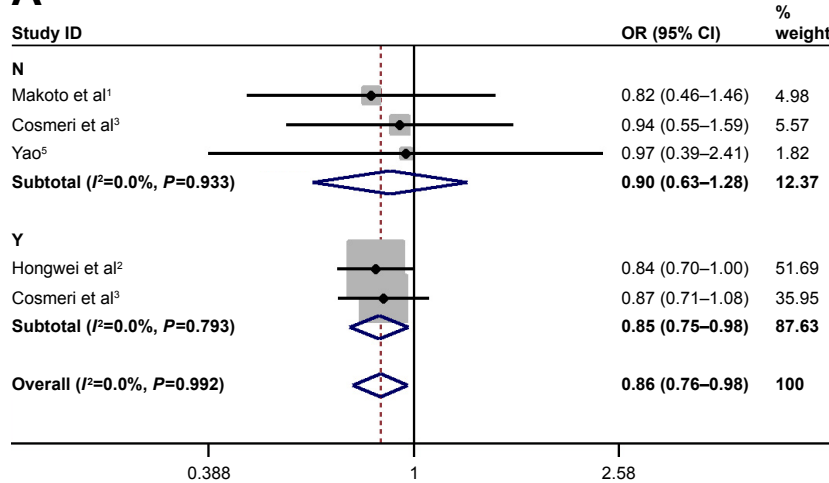

B

\begin{tabular}{|c|c|c|}
\hline Study ID & OR $(95 \% \mathrm{Cl})$ & $\begin{array}{l}\% \\
\text { weight }\end{array}$ \\
\hline \multicolumn{3}{|l|}{$\mathbf{N}$} \\
\hline Makoto et al ${ }^{1}$ & $0.82(0.65-1.03)$ & 15.54 \\
\hline Cosmeri et al ${ }^{3}$ & $0.95(0.64-1.43)$ & 4.48 \\
\hline $\mathrm{Yao}^{5}$ & $-1.04(0.71-1.51)$ & 4.95 \\
\hline Subtotal $\left(I^{2}=0.0 \%, P=0.532\right)$ & $0.89(0.75-1.06)$ & 24.97 \\
\hline \multicolumn{3}{|l|}{$\mathbf{Y}$} \\
\hline Hongwei et $\mathrm{al}^{2}$ & $0.83(0.73-0.95)$ & 45.54 \\
\hline Cosmeri et al ${ }^{3}$ & $0.86(0.73-1.01)$ & 29.49 \\
\hline Subtotal $\left(I^{2}=0.0 \%, P=0.757\right)$ & $0.84(0.76-0.93)$ & 75.03 \\
\hline Overall $\left(I^{2}=0.0 \%, P=0.802\right)$ & $0.85(0.78-0.93)$ & 100 \\
\hline$T$ & & \\
\hline 0.637 & 1.57 & \\
\hline
\end{tabular}

C

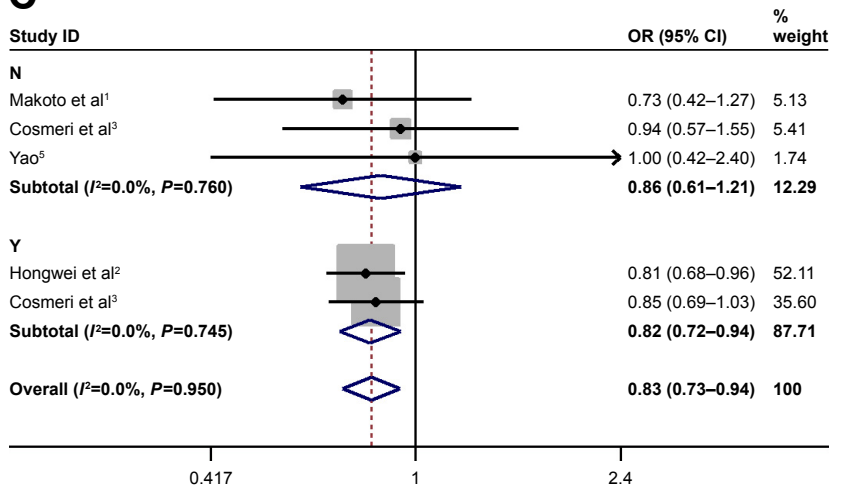

Figure S3 Subgroup analysis of sample size for NR5A2 rs3790843 G>A polymorphism and pancreatic cancer risk.

Notes: (A) GA vs GG; (B) GA+AA vs GG; (C) A vs G. N, the total sample size is smaller than I,000; Y, the total sample size is larger than I,000.

Abbreviation: $O R$, odds ratio. 

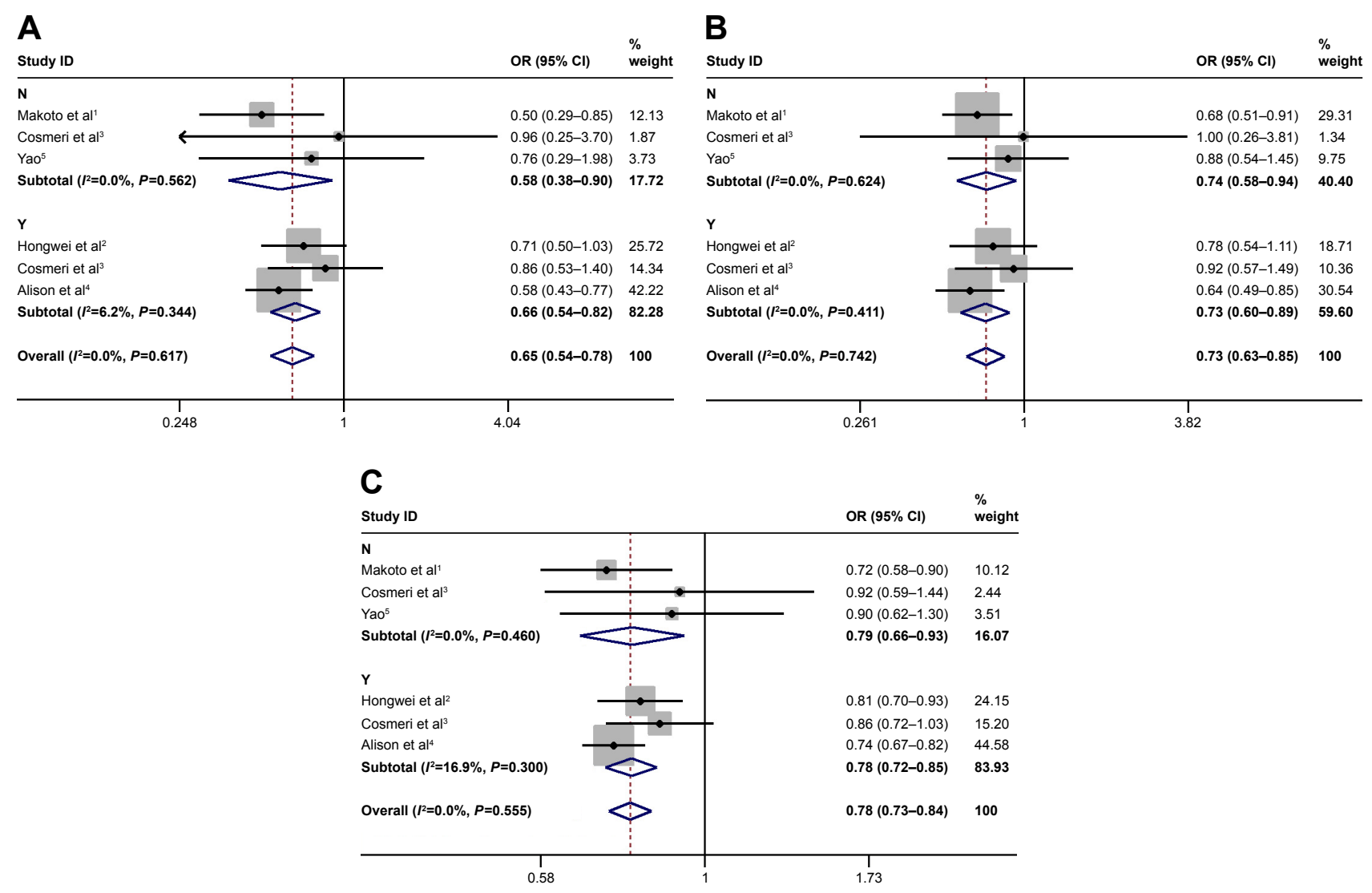

Figure S4 Subgroup analysis of sample size for NR5A2 rs3790844 T>C polymorphism and pancreatic cancer risk.

Notes: (A) CC vs TT; (B) CC vs TT+CT; (C) C vs T. N, the total sample size is smaller than I,000; Y, the total sample size is larger than I,000. Weights are from randomeffects analysis.

Abbreviation: OR, odds ratio.

A
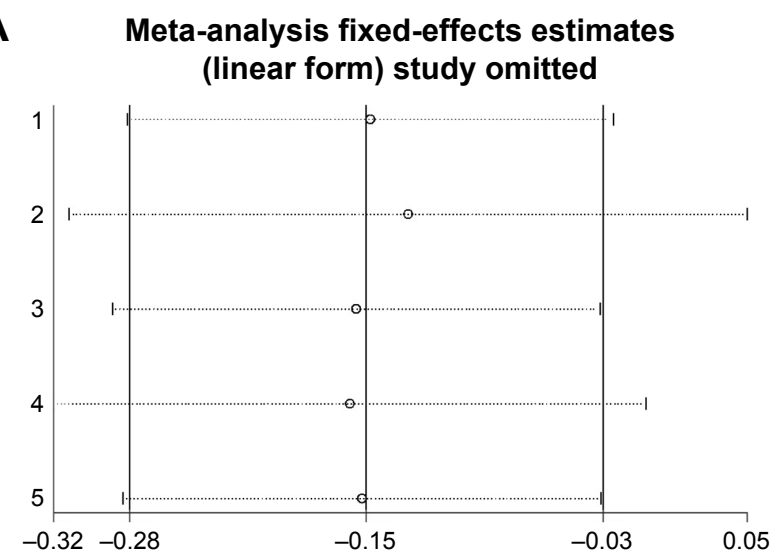

B Meta-analysis fixed-effects estimates (linear form) study omitted

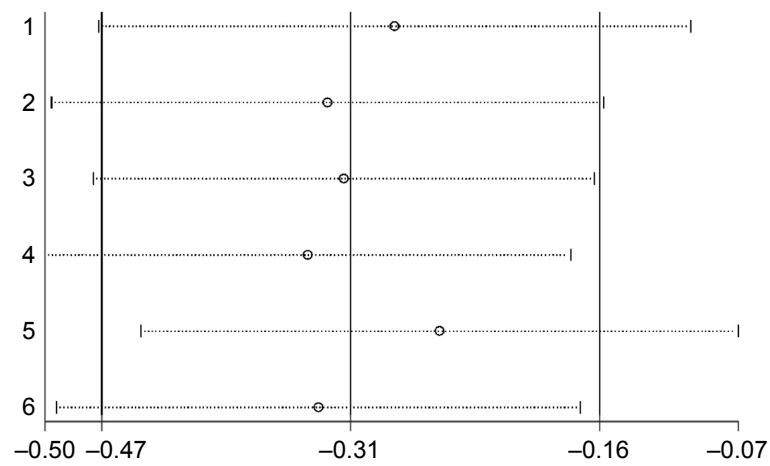

Figure S5 (Continued) 


\section{Meta-analysis fixed-effects estimates (linear form) study omitted}

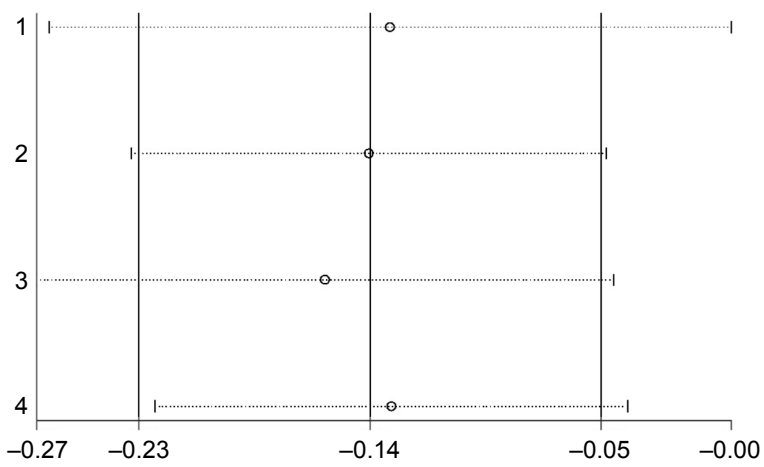

Figure S5 The sensitivity analysis of pancreatic cancer risk associated with NR5A2 polymorphism.

Notes: (A) Heterozygous model (GA vs GG) for rs3790843 G>A; (B) recessive model (CC vs TT+CT) for rs3790844 T>C; (C) allele model (T vs C) for rs I 2029406 $\mathrm{C}>\mathrm{T}$.

\section{References}

1. Makoto U, Shinichi O, Manabu M, et al. Genome-wide association study-identified SNPs (rs3790844, rs3790843) in the NR5A2 gene and risk of pancreatic cancer in Japanese. Sci Rep. 2015;5:17018.

2. Hongwei T, Xiaoqun D, Manal H, et al. Body mass index and obesityand diabetes-associated genotypes and risk for pancreatic cancer. Cancer Epidemiol Biomarkers Prev. 2011;20(5):779-792.

3. Cosmeri R, Daniele C, Nathalia G, et al. Pancreatic cancer susceptibility loci and their role in survival. PLoS One. 2011;6(11):e27921.
4. Alison PK, Sara L, Julie BM, et al. An absolute risk model to identify individuals at elevated risk for pancreatic cancer in the general population. PLoS One. 2013;8(9):e72311.

5. Yao Y. A Case Control Study of Pancreatic Cancer with Environmental, Diease, Psychological, Behavioral Factors and the Preliminary Study of Genetic Predisposition in Pancreatic Cancer.caj [D]. Peking: Peking Union Medical College; 2013.

\section{Publish your work in this journal}

OncoTargets and Therapy is an international, peer-reviewed, open access journal focusing on the pathological basis of all cancers, potential targets for therapy and treatment protocols employed to improve the management of cancer patients. The journal also focuses on the impact of management programs and new therapeutic agents and protocols on

\section{Dovepress}

patient perspectives such as quality of life, adherence and satisfaction. The manuscript management system is completely online and includes a very quick and fair peer-review system, which is all easy to use. Visit http://www.dovepress.com/testimonials.php to read real quotes from published authors. 